\title{
Caio Fernando Abreu e a ditadura militar no Brasil
}

\begin{abstract}
Resumo: O escritor gaúcho Caio Fernando Abreu é contemporâneo de uma geração que viveu os efeitos do golpe militar de 1964. Embora seus textos estejam voltados à perspectiva interior, possuem relações profundas com a realidade e o momento histórico de sua produção. Seus contos apresentam o interior dos indivíduos e as relações problemáticas que os envolvem, reproduzindo as desilusões dos jovens que sofreram as conseqüências da repressão. Assim, este trabalho pretende analisar os contos "London, London ou ajax, brush and rubbish" e "Garopaba mon amour" para observar a contribuição dos textos de Caio para a tarefa de interpretação das condições dos indivíduos numa atmosfera ditatorial.
\end{abstract}

Palavras-chave: Caio Fernando Abreu; Ditadura militar no Brasil; "London, London ou ajax, brush and rubbish"; "Garopaba mon amour".

\begin{abstract}
Writer Caio Fernando Abreu, who was born in the state of Rio Grande do Sul/BR, is contemporary to a generation that experienced the effects of the 1964 coup d'état. Although his texts deal with a subjective and personal perspective, they hold deep relations with the reality and the historical moment of their production. His short stories present the personal identity of the characters and the troublesome situations that surround them, reproducing, then, the disenchantment felt by the youth who suffered the consequences of that period of repression. Thus, this study aims at analyzing the short stories "London, London ou ajax, brush and rubbish" and "Garopaba mon amour", in order to observe the contribution of Caio's texts to the task of interpreting the conditions of life among individuals subjected to a dictatorial atmosphere.
\end{abstract}

Keywords: Caio Fernando Abreu; Military dictatorship in Brazil; "London, London ou ajax, brush and rubbish"; "Garopaba mon amour".

Caio Fernando Abreu é contemporâneo de uma geração que viveu os efeitos do golpe militar de 1964. Embora seus textos estejam voltados à perspectiva interior, não se podem negar suas relações profundas com a realidade e o momento histórico de sua produção. Apresentando o interior dos indivíduos e as relações problemáticas que os envolvem, Caio reproduz as desilusões dos jovens que sofreram as conseqüências da repressão. Dessa forma, além de ser pertinente investigar o panorama de sua vida, sua época e sua obra, é indispensável verificar a relação dos seus textos com o momento histórico e a sua grande contribuição para a representação do indivíduo gaúcho, brasileiro dos últimos anos do século XX.

\footnotetext{
* Aline Azeredo Bizello é graduada em Letras pela Universidade Federal do Rio Grande do Sul e mestranda em Literatura Comparada na mesma Instituição.
} 
Caio Fernando Abreu nasceu em Santiago, cidade do Rio Grande do Sul, no dia 12 de setembro de 1948. Foi contemporâneo da juventude que assistiu ao golpe responsável pela implantação do regime militar em 1964.

Esse aspecto determina a temática da solidão e do medo, presentes em sua literatura, como se lê em Inventário do Irremediável, publicado em 1970.

Diante de uma nova situação e de um mundo sem perspectivas, o brasileiro entrou em conflito com sua identidade. Essa realidade pode ser vista na obra de Caio Fernando Abreu: não, apenas, como a representação da vida social brasileira, mas também, como "uma realidade nova, 'opaca', que não pode ser compreendida, em relação ao seu horizonte de expectativa diretamente, mas apenas através das perguntas que lhe proporcionem uma também renovada percepção do mundo e do problema humano.” (LOBO, 1992, p. 236)

Refletindo essa realidade, em 1970, Caio Fernando Abreu publicou Limite Branco, cujo tema principal é a busca de identidade. Nesse romance, o protagonista questiona os próprios valores e os valores de sua família, formando, ao longo da narrativa, sua personalidade.

Após o golpe militar, a economia nacional sofreu um rápido crescimento. O aumento do produto interno bruto, o desenvolvimento da produção industrial e do mercado interno de consumo contribuíram para a expansão da idéia de que o Brasil estaria passando por um verdadeiro milagre econômico. Em meio a essa situação, Caio Fernando Abreu, depois de viver em São Paulo e Rio de Janeiro, em 1973, viajou exilado para a Europa. Retornou em 1974, quando, no Brasil, o governo do partido da oposição tomou posse. Na economia, o milagre econômico revelava-se uma ilusão. Das margens, manifestava-se um pouco de literatura, cujo ritmo acelerou-se, apenas, com os movimentos de anistia e com a volta dos exilados. Dentro desse contexto, a literatura brasileira transformou-se. A discussão, a conscientização e a crítica sobre o sistema implementado, as questões sociais, os modos de funcionamento de poder e o autoritarismo eram reprimidos e figurados na linguagem para expressar uma posição contra o poder, tal como estava estruturado.

A publicação, em 1975, de O Ovo Apunhalado, representou a preocupação em denunciar esse momento histórico através da criação de alegorias para criticar a sociedade de consumo desumanizada. Embora a obra tenha sido julgada como um atentado contra os bons costumes e, por isso, tenha sofrido alguns cortes, foi considerada uma das melhores do ano pela revista Veja. Aliás, essa obra foi premiada num concurso instituído pelo Instituto Estadual do Livro. Na mesma década, no ano de 1977, outro livro de Caio foi publicado: Pedras de Calcutá, no qual as imagens enigmáticas são freqüentes. Através delas e de uma 
estrutura fragmentada, são expostos os problemas da sociedade e do interior dos indivíduos, inseridos em um contexto de repressão. As metáforas, as imagens inusitadas, as simbologias e as ambigüidades formam o clima de denúncia e apresentam, através da articulação desses elementos, a construção do mundo interior e exterior das personagens, caracterizadas pela falta de perspectiva.

No contexto da ditadura militar brasileira, a resistência manifestava-se não apenas na literatura, mas nos movimentos que buscavam reformas na situação política do país. Em 1979, quando João Figueiredo tomou posse, foi assinada a anistia; voltou o pluripartidarismo e a censura foi abolida. Esses fatores geraram uma nova euforia na população, alimentando suas esperanças. Assim, são apontados novos caminhos para a geração que sofreu as conseqüências do regime militar. Nesse sentido atua a obra de Caio, escrita em 1982: Morangos Mofados. No ano seguinte, ele publica Triângulo das Águas na qual aparecem, assim como em Morangos Mofados, os conflitos entre os instintos das personagens e as regras impostas pela sociedade que não aceita algo distante da moral convencional.

Em 1985, após um acordo entre o governo e as oposições, Tancredo Neves foi eleito presidente por votação indireta. Foi um momento de grande esperança para o retorno da democracia. Com o falecimento de Tancredo, o período de transição passa a ser dirigido por José Sarney.

O Brasil vive, desde então, tentativas de redemocratização. Essa atmosfera de desordem e de processo de mudança aparece em outras obras de Caio, pois no período pósditadura o escritor publicou outros livros que também refletem sua época, como Os Dragões não Conhecem o Paraíso.

Como se nota, a obra de Caio Fernando Abreu possui relações profundas com a realidade histórica. Os relatos de seus textos denunciam o sistema repressor responsável pela privação dos sonhos, ideais e esperanças de liberdade, embora não descrevam de forma explícita a ditadura militar no Brasil. O escritor, com suas personagens, agride o 'status quo' dominante, pois apresenta indivíduos de perfis opostos aos exigidos pela sociedade tradicional: são homens e mulheres fragmentados e destituídos de identidade. Dessa forma, valendo-se de metáforas, Caio desmitifica a visão de identidade una, denunciando, assim, a fragmentação do indivíduo. O escritor cria jogos de linguagem, explora diálogos e monólogos e capta os detalhes da expressão humana. Através de suas obras, lê-se um dos traços de sua especificidade literária: “conciliar, através do discurso, uma visão de mundo catastrófica e anti-utópica, decorrente da repressão política e dos conseqüentes desequilíbrios sociais, a uma outra de natureza psicanalítica.” (MASINA, 1998, p. 174) 
Assim, a denúncia dos efeitos da repressão deixa-se ler nos eixos em torno dos quais giram as histórias de seus textos: a investigação interior e o auto-conhecimento. Com "London, London ou ajax, brush and rubbish" e "Garopaba mon amour" não é diferente. Nesses contos, são apresentados homens que sofreram com o arbítrio do regime ditatorial.

Em "London, London ou ajax, brush and rubbish" são narrados instantes da vida de um indivíduo em Londres, cidade onde, exilado, trabalha como faxineiro esperando o retorno ao Brasil. Como se vê, o título resgata uma das experiências mais emblemáticas da trajetória de Caio Fernando Abreu: o exílio na cidade inglesa durante o qual trabalhou como faxineiro. "Garopaba mon amour" narra instantes de repressão e de preconceito contra um grupo de jovens hippies, homossexuais e drogados numa praia de Santa Catarina.

No conto "London, London ou ajax, brush and rubbish" o protagonista busca referências antigas sobre sua terra natal para resgatar a identidade. A personagem sente-se no vazio e no absurdo da vida moderna e, assim, volta-se para si mesma.

A personagem busca uma ordem interior desfeita pela desintegração da identidade decorrente da repressão. Nesse sentido, a ditadura contribui para a introspecção do homem, pois lhe roubou a liberdade e enclausurou-o num mundo de angústia, solidão e vazio existencial. Para fugir desse vazio e da perseguição da censura, o homem busca exílio interno e externo.

O protagonista de "London, London ou ajax, brush and rubbish" representa essa realidade. Vive uma situação extrema de perda da identidade, pois está distante de seu país de origem e, onde está, sente-se um estrangeiro. É um indivíduo desenraizado, em trânsito, como mostra a seguinte passagem:

Bolhas nas mãos. Calos nos pés. Dor nas costas. Músculos cansados. Ajax, brush and rubbish. Cabelos duros de poeira. Narinas cheias de poeira. Stairs, stairs, stairs. Bathrooms, Bathrooms. Blobs. Dor nas pernas. Subir, descer, chamar, ouvir. Up, down. Up, down. Many times lost me by undergrounds, corners, places, gardens, squares, terraces, streets, roads. Dor, pain. Blobs, bolhas. (ABREU, 1988, p. 49)

A passagem anterior apresenta o homem fragmentado, mergulhado no caos do mundo absurdo no qual vive. A personagem sente, apenas, dor, cansaço, pois perdeu suas raízes e sua liberdade. A neutralização e a diluição do 'eu' do protagonista simboliza esse desajuste entre ele e o mundo.

Esse desajuste revela sua necessidade de encontrar um lugar no mundo. Veja-se a seguinte passagem: "Magrinha, lá na Bahia, localiza minha pequena luz, estende tua mão cheia de anéis por sobre o mar e toca na minha testa caliente de índio latino-americano e fala assim [...]" (ABREU, 1988, p. 52) 
Nota-se, na passagem transcrita acima, o apelo do protagonista para que a "magrinha" localize sua essência em seu país. Tal apelo é indício de um esvaziamento interior.

Esse esvaziamento reflete-se no uso de entorpecentes e na prática sexual sem sentido. Quando caminha pelas ruas da cidade, a questão da sexualidade é sugerida: "Blobs in stranger's hands, virando na privada o balde cheio de sifilização, enquanto puxo a descarga para que Mrs. Burnes não escute meu grito" (ABREU, 1988, p. 49).

Nota-se que a referência a uma doença sexualmente transmissível, a sífilis, é uma forma de subentender a promiscuidade das relações sexuais. Vê-se, dessa forma, que o sexo e as drogas aparecem como a única saída, o único refúgio de um mundo caótico e repressor.

Em "London, London ou ajax, brush and rubbish", a doença e o sexo sem sentido flagram o esboroamento dos indivíduos. A personagem principal, distante do país de origem, sem referência de identidade, caminha e insere-se nesse universo, ratificando o apagamento da personalidade. A impossibilidade de restabelecimento dos laços com o social conduz o protagonista a buscar outras realidades através de alucinógenos:

Eu não quero dizer nada, em língua nenhuma eu não quero dizer absolutamente nada. Eu só sorrio e deixo ela ir embora com seus pés descalços e muito sujos dançando embaixo dos trapos coloridos da saia. Ela canta ainda. Eu aproximo o pulso das narinas e aspiro, até o ônibus chegar, eu aspiro. Sândalo, Oriente. (ABREU, 1988, p. 49)

A personagem nega-se a pronunciar qualquer palavra em qualquer idioma, pois nenhuma palavra será suficiente para expressar seu sentimento de exílio, solidão e abandono. “Assim, entre duas línguas, o seu elemento é o silêncio. De tanto falarmos de diversas maneiras, igualmente banais, igualmente aproximativas, não falamos mais" (KRISTEVA, 1994, p. 23). A repressão contribui para que a personagem não se manifeste e leva-a a interiorizar seus conflitos. Nesse caso, as drogas e os alucinógenos são a via que conduz ao universo interior. Os entorpecentes são o caminho para o conhecimento interno.

Nesse sentido, o processo de criação literária de Caio afirma sua preocupação com o indivíduo excluído, marginalizado, fragmentado e sem identidade.

A fragmentação reflete-se na estrutura das narrativas, tornando-as descontínuas. Em "London, London ou ajax, brush and rubbish", as informações expostas pelo narrador do conto não são claras, pois a experiência da personagem aparece incompleta:

Traz um cinzeiro prata (tailandês) e eu apago meu cigarro (americano). But, sometimes, yo hablo también un poquito de español e, if il faut, aussi un peu de français: navego, navego nas waves poluídas de Babylon City, depois sento no Hyde Park, W2, e assisto ao encontro de Carmenmiranda com uma Rumbeira-From-Kiúba. (ABREU, 1988, p. 48)

A passagem evidencia um discurso no qual tempos, espaços e línguas confundem-se. Essa confusão representa a dificuldade da personagem em encontrar algo que lhe seja 
próprio, pois o emprego de faxineiro numa casa londrina obriga-o a falar uma língua que não é a sua. Assim, sem poder expressar-se em sua língua materna, enfatiza seu processo de fragmentação e cria uma realidade na qual o discurso não obedece, apenas, a um idioma. Diante desse caos interior, navega em vários locais da cidade e cria um espaço onírico no qual apresenta duas referências que o identificam como brasileiro e latino-americano, respectivamente: Carmenmiranda e a Rumbeira-From-Kiúba.

Nota-se que, ao indicar a impossibilidade da personagem de comunicar-se em seu próprio idioma, Caio apresenta a situação de exílio que ele próprio vive e desvela, implicitamente, o sentimento do indivíduo brasileiro no período ditatorial.

Na realidade, a sobreposição de espaços, na narração, é decorrente da mescla de lembranças e fantasias. Esses deslocamentos espaciais representam os desdobres dos deslocamentos do pensamento (BOURNEUF, 1976). Dessa forma, a descrição simultânea sobre acontecimentos ocorridos em Babylon City, Hyde Park e W2 manifesta o desejo de fuga da personagem. Ela escapa da descrição da vida difícil para mergulhar no mundo do 'faz de conta', tentando, assim, resgatar sua identidade perdida. Tenta alcançar tal objetivo buscando referências que identifiquem sua nacionalidade e, ao mesmo tempo, confunde essas referências com as experiências que está vivendo.

Essas circunstâncias pouco precisas, aliadas aos desdobres temporais e espaciais, identificam o inventário fragmentado do interior do protagonista. A fragmentação decorre de sua situação de exílio. Longe de seu país, ele é o outro, o diferente:

"Something else. [...] É um frágil falo verde, coberto de espinhos brancos. [...] Mas nada acontece. Something else. Eu queria tocar Pour Élise ao piano, sabia? É meio kitsch, eu sei, mas eu queria, e nel Brazil, cariño, nel otro lado del mar, hay una tierra encantada que se llama Arembepe, y un poco más al sur hay otra, que se llama Garopaba. En esos sitios, todos los dias son sunny-days, todos”. (ABREU, 1988, p. 50)

É homossexual e exilado, isto é, a diferença caracteriza a personagem. O conflito de ser diferente aponta o apagamento de sua identidade. A menção ao falo deixa ler sua homossexualidade, pois se trata de um falo diferente: frágil e coberto de espinhos brancos, incapaz de modificar as bolhas brancas dos dedos. Assim, torna-se visível o conflito com a personalidade gay. O conflito da diferença estende-se para a condição do exílio. A busca incessante por algo que não o faça perder as referências nacionais manifesta-se na caracterização positiva das cidades brasileiras. Obrigada a viver e a ver outras paisagens - a cidade inglesa fria e cinzenta -, a personagem manifesta a saudade das condições climáticas de seu país, principalmente dos dias de sol. A distância leva o indivíduo a esquecer as 
condições que o conduziram ao exílio e a idealizar a terra natal como uma terra encantada onde se vivem, apenas, dias felizes.

A descrição idealizada representa o desejo de voltar para casa e juntar todos os fragmentos que se dispersaram:

\begin{abstract}
"Mon cher, apanhe suas maracas, suas malhas de balé, seus pratos chineses - apanhe todos os pedaços que você perdeu nessas andanças e venha para meu tapete mágico. Te quieres volar conmigo hasta los sitios encantados? Something else." (ABREU, 1988, p. 50)
\end{abstract}

Veja-se que a causa da redução de seu universo existencial é atribuída à condição de exilado. Em cada lugar onde teve de exilar-se perdeu um pouco de si. Para se reencontrar, necessita olhar para algo que o identifique: seu lugar de origem. Como afirma Kristeva (1994), embora o exilado seja estranho à própria terra, desconhece essa informação, pois está incumbido de vencer o desafio de encontrar um caminho. "Orgulhoso, agarra-se altivamente ao que lhe falta, à ausência, a qualquer símbolo" (KRISTEVA, 1994, p.13).

No decorrer da narrativa, torna-se mais óbvia a difícil condição estrangeira:

É fácil, magro, tu desdobra numa boa: primeiro procura apartamento, depois trabalho, depois escola, depois, se sobrar tempo, amor. Depois, se preciso for, e sempre é, motivos para rir ou chorar - ou qualquer coisa mais drástica, como viciar-se definitivamente em heroína, fazer auto-stop até o Katmandu, traficar armas para o Marrocos ou - sempre existe old fashion morrer de amores por alguém que tenha nojo de sua pele latina. (ABREU, 1988, p. 51)

Nota-se que o caráter polimorfo da fala permanece e é ratificado pela mistura de sentimentos ambíguos: rir e chorar, amar quem tem nojo de estrangeiros. A oralidade da linguagem permite observar as diversas faces do pensamento e a informalidade do discurso. Dessa forma, a ambigüidade é garantida, favorecendo o aparecimento de um fio de ironia quanto à condição de exílio vivida pelo protagonista. Assim, todos os desdobres da imaginação apresentados anteriormente pela personagem, nesse ponto da narrativa, são explicados com maior clareza. Ser latino em terra britânica é o mesmo que ser nada, pois não é brasileiro nem inglês: é um estrangeiro, fragmentado e diluído.

A condensação temporal é decorrente da fragmentação do indivíduo e caracteriza a falta de perspectiva de um mundo exterior e de um mundo interior, pois o protagonista busca a si mesmo, ao mesmo tempo em que constrói a consciência da perda da própria identidade.

O conto "Garopaba mon amour" também é formado de imagens condensadas; por isso, a experiência das personagens aparece incompleta. O conto ressalta a descoberta da Ilha de Santa Catarina pelos gaúchos. A praia de Garopaba é o próprio paraíso: uma beleza natural pouco modificada pela mão humana. O primeiro parágrafo do texto narra a chegada de um grupo de jovens na praia. Hábitos típicos da geração de 70: reunião entre amigos numa praia de Santa Catarina, ao som de um violão. Misturada a esse relato inicial e a outros, há a 
exposição da violência que se manifesta entre as personagens. A primeira expressão dessa violência aparece num diálogo. Nele, uma pessoa exige que a outra conte algo, ameaçando-a com constrangimento físico e moral. Enquanto o protagonista é preso e maltratado, recordase do dia anterior e prossegue uma conversa com o mar. Nesse momento, registram-se mesclas temporais:

\begin{abstract}
Mar, ainda não te falei de ontem. Talvez não haja mais tempo. Não sei se sairei vivo. Ontem lavamos na fonte os cabelos um do outro. Depositamos a vela acesa sobre o muro. Pedir o que agora, Mar? Se para sempre teremos medo. Da dor física, tapa na cara, fio no nervo exposto do dente. Meu corpo vai ficar marcado pelo roxo das pancadas, não pelo roxo dos teus dentes em minha carne. (ABREU, 1988, p. 44)
\end{abstract}

A passagem evidencia a tortura e a ditadura através de um discurso no qual a violência sofrida naquele momento, os instantes felizes vividos no dia anterior e o medo do dia seguinte confundem-se. Dessa forma, são os estados internos da personagem que controlam o tempo da narrativa, tornando-a subjetiva (cf. NUNES, 1995).

O discurso subjetivo representa o medo causado pela privação da liberdade e pela rejeição ao diferente: o indivíduo não pode viver conforme suas escolhas, porque será punido e violentado. Vê-se, assim, a transgressão de Caio levada às últimas consequiências. Ao escrever sobre o mundo gay, o escritor rompe com a narrativa gaúcha convencional, pautada no símbolo do monarca das coxilhas: conotação de um mundo positivo e livre, ou seja, um mundo oposto ao do indivíduo apresentado por Caio, que busca tornar visível o até então interdito e censurado mundo gay. A fragmentação reproduz a frustração de uma geração urbana e reprimida que se extraviou e buscou refúgio nas drogas e nas orgias sexuais. Tanto assim que o apelo carnal e homossexual, nesse texto, é sugerido através do mar como metáfora do homem:

Mar veio correndo pelo calçamento antigo na frente da Igreja, os braços estendidos em direção a ele [...] Mar veio correndo sobre as carruagens, as sinhás-moças, os pés cascudos e pretos. Nos chocaremos agora, no próximo segundo, nossos rostos afundados nos ombros um do outro não dirão nada, e não será preciso: neste próximo abraço deste próximo segundo para onde corro também, os braços abertos nessas pedras de um tempo morto e mais limpo. (ABREU, 1988, p. 43)

A passagem acima permite perceber que a manifestação da homossexualidade da personagem é oprimida de tal forma que a assunção dessa identidade aparece camuflada pela simbologia do mar. O mar, no decorrer da narrativa, representa o amor excêntrico. Tal situação leva à redução do mundo existencial da personagem.

O mundo do indivíduo reduz-se a ponto de, num mesmo parágrafo, haver a transcrição de uma conversa entre as personagens sem diferenciação entre as falas de cada interlocutor, pois não há travessão nem separação de linhas: "Pena tenho eu de você, que 
precisa se sujeitar a esse emprego imundo: eu sou um ser humano decente e você é um verme. Revoltadinha a bixa. Veja como se defende bem” (ABREU, 1988, p. 43).

Nesse diálogo, há uma justaposição das vozes de narrador e personagens. Essa mistura sugere uma ironia mordaz: o gay tem que se defender. O indivíduo reprimido, sem liberdade e excluído da hierarquia social está esvaziado de sua identidade a ponto de sua voz diluir-se e misturar-se com outras vozes. Essa diluição deve-se à maior objetivação do material da história. A união entre as falas das personagens garante um contraponto de perspectivas que desenvolve a narrativa. A presença do diálogo sem diferenciação das falas dos interlocutores é decorrente do choque entre a palavra e a contra-palavra que se fundem em uma só enunciação e em um só emissor (cf. BAKHTIN, 1997).

Em "Garopaba mon amour", o uso de drogas surge, também, como um hábito das personagens: "O chão amanheceu juncado de latas de cerveja copos de plástico papéis amassados pontas de cigarro seringas manchadas de sangue latas de conserva ampolas vazias vidros de óleo de bronzear bagas bolsas de couro fotonovelas tamancos ortopédicos." (ABREU, 1988, p. 41)

Vê-se que a descrição acima apresenta indivíduos com hábitos e comportamentos que alteraram a fisionomia do espaço, denotando a busca do indivíduo por um refúgio, por um lugar onde possa agir de acordo com suas preferências e escolhas. No conto, o refúgio não garante a liberdade, pois a repressão controla, inclusive, as manifestações sexuais. O sexo, nesse texto de Caio, surge como comprovação de sua condição de oprimido: a personagem gay representa a preferência sexual adversa aos padrões vigentes. $\mathrm{O}$ homossexual é sufocado pela sociedade que não aceita comportamentos distintos dos estabelecidos. Em conseqüência, a ditadura censura e exclui o diferente, privando o homem da liberdade.

Como se nota, a polivalência da palavra literária torna a interpretação mais ampla, porém limitada. Em outras palavras, todo texto possui convenções lingüísticas determinantes da relação entre texto e contexto, pois a literatura inclui-se na história

Dessa forma, através de pequenos fragmentos e da investigação interior de suas personagens, Caio Fernando Abreu revela a relação entre sua criação literária e o seu momento histórico. Tal fato permite confirmar que Caio era um escritor atento para as necessidades da época. Essa afirmação pode ser comprovada pela escolha do autor em concentrar-se nas personagens representantes do indivíduo do final do século $\mathrm{XX}$ : o indivíduo excluído e fragmentado.

Assim, nota-se a contribuição dos textos de Caio para a tarefa de interpretação das condições dos indivíduos numa atmosfera ditatorial. Através do caos vivido por suas 
personagens, percebe-se a peculiaridade dos seus textos e procura-se entender as relações entre o momento histórico e os processos de produção literária.

\section{Referências}

ABREU, Caio Fernando. Mel e Girassóis. Porto Alegre: Mercado Aberto, 1988. . Pedras de Calcutá. São Paulo: Alfa-Omega, 1977. . Inventário do Ir-remediável. Porto Alegre: Sulina, 1995. . Morangos Mofados. São Paulo: Brasiliense, 1986. . O Ovo Apunhalado. Porto Alegre: Globo, 1976. . Limite Branco. São Paulo: Siciliano, 1994. .Triângulo das Águas. São Paulo: Siciliano, 1991. .Os Dragões não Conhecem o Paraíso. São Paulo: Companhia das Letras, 1988.

BAKHTIN, Mikhail. Problemas da Poética de Dostoiévski. Rio de Janeiro: Forense, 1981. BOSI, Alfredo. História concisa da Literatura Brasileira. São Paulo: Cultrix, 1994.

BITTENCOURT, Gilda Neves da Silva. O conto sul-rio-grandense: tradição e modernidade. Porto Alegre: Universidade Federal do Rio Grande do Sul, 1999.

BOURNEUF, Roland. O espaço. In: O universo do romance. Coimbra: Almedina, 1976.

BRAIT, Beth. A personagem. São Paulo: Ática, 1985.

CANDIDO, Antonio et alii. A personagem de ficção. São Paulo: Perspectiva, 1972.

CORTÁZAR, Julio. Valise de Cronópio. São Paulo: Perspectiva, 1974.

GOTLIB, Nádia. Teoria do Conto. São Paulo: Ática, 1985.

HALL, Stuart. A identidade cultural na pós-modernidade. Tradução de Tomaz Tadeu da Silva. 3. ed. Rio de Janeiro: DP\&A, 1999.

INSTITUTO ESTADUAL DO LIVRO. Caio Fernando Abreu. Porto Alegre: Ulbra, 1995.

KRISTEVA, Julia. Estrangeiros para nós mesmos. Rio de Janeiro: Rocco, 1994.

LEITE, Ligia Chiappini Moraes. O foco narrativo. São Paulo: Ática, 2002. 
LOBO, Luísa. O leitor. In: JOBIM, José Luis (Org.). Palavras da Crítica: tendências e conceitos no estudo da literatura. Rio de Janeiro: Imago, 1992.

MAROBIN, Luiz. Painéis da Literatura Gaúcha. São Leopoldo: UNISINOS, 1995.

MASINA, Léa. Caio Fernando Abreu. In: SANTOS, Volnyr e SANTOS, Walmor (Org.). Antologia Crítica do Conto Gaúcho. Porto Alegre: Sagra Luzzatto, 1998.

MOISÉS, Massaud. A criação literária. São Paulo: Melhoramentos, 1970.

MORA, Gabriela. En torno al cuento: de la teoría general y de su práctica en hispanoamerica. Madrid: José Porrúa Turanzas, 1985.

MESQUITA, Samira Nahid de. O enredo. São Paulo: Ática, 1987.

NUNES, Benedito. O tempo na narrativa. São Paulo. Ática, 1995.

POE, Edgar Allan. A filosofia da composição. In: Poemas e ensaios. Rio de Janeiro: Globo, 1985.

PORTELLA, Eduardo. Literatura e realidade nacional. Rio de Janeiro: Tempo brasileiro, 1975.

TACCA, Oscar. As vozes do romance. Madrid: Gredos S. A., 1978.

ZILBERMAN, Regina. A literatura no Rio Grande do Sul. Porto Alegre: Mercado Aberto, 1982.

. Temperamento de contista. In: ABREU, Caio Fernando. Mel e Girassóis. Porto Alegre: Mercado Aberto, 1988. 